\title{
Application of TOPSIS to Financial Comprehensive Assessment of Power Listed Companies
}

\author{
Jian-ying Lou, Xiang Gao and Qian Cui \\ Department of Economic, China University of Geosciences Great Wall College, \\ Baoding,071000, China
}

Keywords: Power company; Financial capability; TOPSIS; Multi-objective decision

\begin{abstract}
Firstly, according to the characteristics of the power listed companies, a comprehensive evaluation system of its financial capacity is established. Then, the technique for order preference by similarity to ideal solution which can make the multi-objective decision is applied in evaluating power listed companies' financial capability. Finally, a specific example is implement which demonstrates that the proposed method can be extended to solve other similar evaluation problems.
\end{abstract}

\section{Introduction}

The power industry is a highly capital-intensive industries. When it need to expand it production, the internal financing alone is a great difficulty, and public financing is an effective way to attract funds. With the advance of power market-oriented reform, the power industry gradually lost its privileged position. The power listed companies increasingly rely on their own performance, in order to establish the confidence of investors and seek investment. Financial comprehensive capability is the key for company development. Therefore, evaluating the power listed companies' financial capacity is of great significance [1,2].

Under the electric power organizational reform's background, as a result of introducing competitive system, implementing the separate between factory and net, brings the varying degree for the thermal power enterprise the operational risk, simultaneously financial structure of high ratio of debt also gives various thermal power enterprises to bring the huge financial risk. Once the thermal power enterprise has the difficult position, cannot repay the due debt, the thermal power enterprise has to face the financial crisis and even the bankruptcy, these have brought the huge challenge for our country thermal power enterprise. Therefore, it is a urgent and realistic topic that carries on the analysis, the appraisal to the thermal power enterprise finance risk, establishes the finance warning system of thermal power enterprise[3,4].

The financial risk appraisal system is basic safeguard for the enterprise production operation, various countries proposed many theories and the research techniques, the development is quite mature. But it is also lacking in using the fuzzy mathematics analysis method to carry on the thermal power enterprise finance risk assessment systematically comprehensively in our country, therefore, this aspect's research will be advantageous to the theory deepening of business finance risk assessment and analysis. Unify the thermal power enterprise finance risk assessment and the fuzzy mathematics method, is advantageous to comprehensively grasping the financial risk aspect' $s$ questions after the thermal power enterprise electric power organizational reform, to carrying out the financial risk guard policies and the effect, to strengthening business finance control system, creates advantage for the advancement profession health, steady marches into the market competition mechanism[5,6].

Technique for order preference by similarity to ideal solution (TOPSIS) is known as a multi-objective decision analysis approach to sorting method ideal solution. Its main advantages are: the data distribution and the sample size, the number of non- restricted indicator, not a complex mathematical calculations, both for small sample data, this also applies to a variety of large-scale systems; evaluation object can be either spatially. It can be on time, a wide range of applications, with an intuitive sense of geometry, using the raw data more fully, less information loss $[7,8]$. 


\section{Power listed companies' financial capability comprehensive evaluation index system}

Financial comprehensive capability involves a lot of indicators.

According to the characteristics of the power companies and the reality of data accessibility, a evaluation index system is constructed which contains five levels and 21 specific indicators. In this index system, the relationship between corporate financial indicators is under considering, and the national capital performance evaluation index is also under referring. The specific structure is shown as follows:

(1) Debt paying ability. The indicators which measure the short-term solvency include liquidity ratio (B1) and the cash ratio (B2). The indicators which measure long-term solvency include the asset-liability ratio (B3), shareholders' equity ratio (B4) and debt to equity ratio (B5).

(2) Cash capability, which can reflect cash flow information. The specific indicators include cash dividend payout ratio (B6), cash self-sufficiency rate (B7) and net cash flow per share (B8).

(3) Development ability, which is a longitudinal analysis of the financial indicators of enterprises compared with previous years. The specific indicators include main business revenue growth (B9), net profit growth (B10), accounts receivable growth rate (B11) and earnings per share growth rate (B12).

(4) Profitability, which means a ability to obtain corporate profits. It is an important indicator to measure the rapid development ability of enterprise. The specific indicators include earnings per share (B13), the total return on assets (B14), main business profit margins (B15) and return on equity (B16).

(5) Operating capacity, which reflect the business management, the turnover rate of capacity utilization of funds, usually faster production and operating assets, the higher the efficiency of assets. The specific indicators include accounts receivable turnover ratio (B17), inventory turnover (B18), flow Asset Turnover (B19), fixed asset turnover (B20) and total asset turnover (B21).

\section{TOPSIS principle}

Companies are always in the complicated operation of objective economic environment Its financial position is subject to market conditions, environmental conditions, financial situation and economic and other factors. The comprehensive evaluation of their financial capability is a multiobjective, multi-level decision-making issue, which is suitable for evaluation of TOPSIS. The method can be directly used statements of listed companies audited data obtained comprehensive capabilities for enterprise financial evaluation, which is more scientific, standardized. In addition, is is suitable for any company whose financial accounting system is sound and reporting is accurate. Using some arithmetic calculation software will be more simple and easy to operate [5].

TOPSIS method is used in the evaluation of the comprehensive financial capability, which is to find a comparison reference value, the ideal solution and negative ideal solution. The ideal solution means the best and worst index value of the same indicators in a company over years. The negative ideal solution means the best and worst index value of the company in the same industry. Considering the index value for each program with the ideal solution and the negative ideal solution, the closer with the ideal solution, the better illustrate the financial capacity [6].

\section{Financial capability comprehensive evaluation based on TOPSIS}

Setting up $n$ companies financial ability to carry out a comprehensive evaluation, and the comprehensive evaluation index system containing $m$ indicators. Each company is marked as $X_{i}=\left(X_{i 1}, X_{i 2}, \cdots, X_{i m}\right), i=1,2, \cdots, n$.

(1) Original data through synthetic treatment with the format of matrix is shown as follows: 


$$
X=\left[\begin{array}{cccc}
x_{11} & x_{12} & \cdots & x_{1 m} \\
x_{21} & x_{22} & \cdots & x_{2 m} \\
\vdots & \vdots & \cdots & \vdots \\
x_{n 1} & x_{n 2} & \cdots & x_{n m}
\end{array}\right] .
$$

(2) The dimensionless of data. The dimensionless processing can refer to Eq.(2). The matrix after dimensionless is marked as $Y$.

$$
\begin{aligned}
y_{i j} & =\frac{x_{i j}}{\sqrt{\sum_{h=1}^{n} x_{h j}^{2}}} \\
Y & =\left[\begin{array}{cccc}
y_{11} & y_{12} & \cdots & y_{1 m} \\
y_{12} & y_{22} & \cdots & y_{2 m} \\
\vdots & \vdots & \cdots & \vdots \\
y_{n 1} & y_{n 2} & \cdots & y_{n m}
\end{array}\right] .
\end{aligned}
$$

(3) Construct the weighted data matrix $Z$, which its element $z_{i j}$ is defined as follows:

$$
z_{i j}=w_{j} \cdot y_{i j} \text {. }
$$

Where $w_{j}$ represents the weight of ${ }^{j}$ th indicator. The analytic hierarchy process is used in this paper to determine the weight.

(4) Determine the ideal value and the negative ideal value, respectively form ideal value vector $Z^{+}$and the negative ideal value vector $Z^{-}$.

$$
\begin{aligned}
& Z^{+}=\left(z_{1}^{+}, z_{2}^{+}, \cdots, z_{m}^{+}\right) . \\
& Z^{-}=\left(z_{1}^{-}, z_{2}^{-}, \cdots, z_{m}^{-}\right) .
\end{aligned}
$$

Where

$$
\begin{gathered}
z_{j}^{+}=\max \left(z_{1 j}, z_{2 j}, \cdots, z_{n j}\right) \\
z_{j}^{-}=\min \left(z_{1 j}, z_{2 j}, \cdots, z_{n j}\right) .
\end{gathered}
$$

(5) Calculate the evaluation index vector objects and the distance between the ideal value vector. Distance formula using Euclidean distance formula, namely:

$$
\begin{aligned}
& D_{i}^{+}=\sqrt{\sum_{j=1}^{m}\left(z_{i j}-z_{i}^{+}\right)^{2}} \\
& D_{i}^{-}=\sqrt{\sum_{j=1}^{m}\left(z_{i j}-z_{i}^{-}\right)^{2}}
\end{aligned}
$$

(6) Calculate relative proximity between the evaluation objects index vector with the ideal value vector according to Eq.(11).

$$
C_{i}=\frac{D_{i}^{-}}{D_{i}^{+}+D_{i}^{-}}
$$

(7) Sort the evaluation object according to the close degree. For $C_{i}$ ranging from 0 to 1 , when the evaluation object index vector equals the ideal value vector, $C_{i}$ equals 1 . On the contrary, when the evaluation object index vector equals the negative ideal value vector, $C_{i}$ equals 0 . When $C_{i}$ is more close to 1 , the corresponding evaluation objects should be at the top. 
In this method, the construction of ideal vector value and negative ideal vector value is a crucial step, which are usually selected in the data matrix after dimensionless processing for its convenience. But there also exists obvious flaws, and the most important is the lack of stability. When the judgment of the environment and their own conditions change, the index value will change accordingly. It may cause changes in the value of the ideal value, and negative ideal vector, the discharge the order also change, the evaluation results will not be unique. Another improved approach is that the ideal vector value and negative vector value are obtained through weighting for each index value.

\section{Specific example and results analysis}

6 power company are selected in this paper as the sample for financial comprehensive capability evaluation based on TOPSIS. The specific data is shown in Table 1.

\begin{tabular}{|c|c|c|c|c|c|c|}
\hline $\begin{array}{l}\text { Compa } \\
\text { ny label }\end{array}$ & 1 & 2 & 3 & 4 & 5 & 6 \\
\hline B1 & 2.266 & 1.84 & 1.461 & 0.653 & 1.603 & 1.795 \\
\hline B2 & 36.66 & $\begin{array}{c}43.7 \\
8\end{array}$ & 38.78 & 42.64 & 32.34 & 30.22 \\
\hline B3 & 63.34 & $\begin{array}{c}51.5 \\
6\end{array}$ & 59.84 & 53.41 & 36.17 & 56.53 \\
\hline B4 & 57.89 & $\begin{array}{c}84.9 \\
1\end{array}$ & 64.8 & 79.83 & 89.4 & 53.45 \\
\hline B5 & 151.32 & $\begin{array}{c}50.9 \\
8\end{array}$ & 224.34 & 70.54 & 123.91 & 89.91 \\
\hline B6 & 1.915 & $\begin{array}{c}1.49 \\
1\end{array}$ & 1.076 & 1.332 & 1.001 & 1.29 \\
\hline B7 & 45.53 & $\begin{array}{c}43.5 \\
9\end{array}$ & 16.26 & 47.29 & 67.82 & 79.67 \\
\hline B8 & 0.56 & 0.57 & 0.23 & 0.69 & 1.93 & 0.99 \\
\hline B9 & 0.31 & $\begin{array}{c}29.1 \\
2\end{array}$ & 3.7 & 40.66 & 14.36 & 3.29 \\
\hline B10 & -27.32 & -7.01 & -21.66 & -10.48 & 27.31 & 12.5 \\
\hline B11 & 29.16 & $\begin{array}{c}19.4 \\
2\end{array}$ & -36.22 & 8.96 & -3.66 & -45.78 \\
\hline B12 & -39.83 & -7.08 & -20 & -18.5 & 5.71 & 12.31 \\
\hline B13 & 0.15 & 0.42 & 0.08 & 0.58 & 0.42 & 0.45 \\
\hline B14 & 6.84 & 6.47 & 1.3 & 10.43 & 13.61 & 16.64 \\
\hline B15 & 6.47 & 8.92 & 1.56 & 14.35 & 18.46 & 18.76 \\
\hline B16 & 7.73 & $\begin{array}{c}17.3 \\
5\end{array}$ & 9.8 & 36.68 & 13.24 & 21.18 \\
\hline B17 & 18.84 & $\begin{array}{c}10.1 \\
5\end{array}$ & 1.76 & 9.38 & 10.38 & 7.79 \\
\hline B18 & 24.67 & $\begin{array}{c}29.8 \\
4\end{array}$ & 10.29 & 21.67 & 18.63 & 11.98 \\
\hline B19 & 2.54 & 0.84 & 0.19 & 1.25 & 1.97 & 1.49 \\
\hline $\mathrm{B} 20$ & 0.79 & 1.06 & 0.27 & 0.57 & 0.94 & 0.79 \\
\hline B21 & 0.59 & 0.31 & 0.11 & 0.24 & 0.49 & 0.47 \\
\hline
\end{tabular}

The original data after the synthetic and dimensionless processing are shown in Table 2 . 
Table 2: Power listed company's financial capacity reprocessing evaluation data

\begin{tabular}{ccccccc}
\hline Company Label & 1 & 2 & 3 & 4 & 5 & 6 \\
\hline B1 & 0.561 & 0.355 & 0.268 & 0.175 & 0.295 & 0.342 \\
B2 & 0.332 & 0.278 & 0.313 & 0.285 & 0.376 & 0.402 \\
B3 & 0.377 & 0.307 & 0.356 & 0.318 & 0.215 & 0.337 \\
B4 & 0.286 & 0.342 & 0.303 & 0.333 & 0.253 & 0.236 \\
B5 & 0.364 & 0.123 & 0.539 & 0.169 & 0.298 & 0.216 \\
B6 & 0.505 & 0.393 & 0.284 & 0.351 & 0.264 & 0.341 \\
B7 & 0.273 & 0.261 & 0.098 & 0.284 & 0.407 & 0.478 \\
B8 & 0.183 & 0.185 & 0.075 & 0.226 & 0.629 & 0.323 \\
B9 & 0.006 & 0.514 & 0.065 & 0.718 & 0.254 & 0.058 \\
B10 & -0.485 & -0.124 & -0.385 & -0.186 & 0.485 & 0.222 \\
B11 & 0.138 & 0.092 & -0.171 & 0.042 & -0.017 & -0.216 \\
B12 & -0.613 & -0.109 & -0.308 & -0.285 & 0.088 & 0.189 \\
B13 & 0.108 & 0.304 & 0.058 & 0.417 & 0.304 & 0.323 \\
B14 & 0.214 & 0.203 & 0.041 & 0.327 & 0.427 & 0.522 \\
B15 & 0.166 & 0.229 & 0.04 & 0.368 & 0.474 & 0.481 \\
B16 & 0.128 & 0.288 & 0.163 & 0.609 & 0.219 & 0.352 \\
B17 & 0.479 & 0.258 & 0.045 & 0.238 & 0.255 & 0.198 \\
B18 & 0.211 & 0.255 & 0.088 & 0.186 & 0.159 & 0.103 \\
B19 & 0.504 & 0.167 & 0.038 & 0.248 & 0.391 & 0.296 \\
B20 & 0.346 & 0.439 & 0.118 & 0.247 & 0.411 & 0.345 \\
B21 & 0.478 & 0.253 & 0.081 & 0.196 & 0.395 & 0.382 \\
\hline
\end{tabular}

After calculation, $C_{i}$ and sort results are required, which are shown in Table 3.

Table 3: Calculation results

\begin{tabular}{ccccccc}
\hline Company label & 1 & 2 & 3 & 4 & 5 & 6 \\
\hline $\mathrm{Ci}$ & 0.423 & 0.481 & 0.187 & 0.516 & 0.608 & 0.526 \\
Rankings & 5 & 4 & 6 & 3 & 1 & 2 \\
\hline
\end{tabular}

The traditional method is used to implement the same sample. The comparison results are shown in Table 4.

Table 4: Comparison between TOPSIS and traditional method

\begin{tabular}{ccccccc}
\hline Company label & 1 & 2 & 3 & 4 & 5 & 6 \\
\hline $\begin{array}{c}\text { Traditional } \\
\text { rankings } \\
\begin{array}{c}\text { TOPSIS } \\
\text { rankings }\end{array}\end{array}$ & 5 & 5 & 6 & 3 & 1 & 2 \\
\hline
\end{tabular}

From the above analysis we can conclude that the evaluation results based on TOPSIS is consistent with the traditional method, which can also indicate that the proposed model applied in evaluating company financial capability is feasible. Therefore, the establishment of indicators and weights are very important to solicit the opinions of experts, while people who do not normally try to avoid interfering factors, to ensure scientific and rational evaluation results.

Compared with the traditional wall evaluation method, comprehensive evaluation method, the state capital performance evaluation method in several or one financial ratios, TOPSIS method can comprehensively consider the relationship among the earnings, the enterprise development, debt paying ability, operation ability and cash ability. Moreover, the proposed method can consider the relative influence degree of the financial ability evaluation result and overcome the above of the 
evaluation index, and the limitation of enterprise evaluation scope, effectively realized the comprehensive evaluation. This method is especially suitable for solution to two or more enterprise financial capability evaluation, and has a good applicability.

\section{Conclusions}

The TOPSIS applied in evaluating the power listed company's financial capability can take full advantage of the method mentioned above and its result is fair and objective. Therefore this proposed model can provides the basis for investment decisions, but also for the power enterprise timely and reasonable analysis of internal adjustment to provide data to support the existence of deficiencies .

\section{References}

[1] Alberto Vega, Juan Aguarón, Jorge García-Alcaraz, José María Moreno-Jiménez. Notes on Dependent Attributes in TOPSIS. Procedia Computer Science. 31 (8), pp. 308-317,2014.

[2] Amelia Bilbao-Terol, Mar Arenas-Parra, Verónica Cañal-Fernández, José Antomil-Ibias. Using TOPSIS for assessing the sustainability of government bond funds. Omega. 49(13), pp. 1-17,2014.

[3] Ting Wang, Bing chuan Xin, Li juan Qin. AHP-Based Capacity Evaluation of Enterprise Development. Procedia Engineering. 15 (11), pp. 4693-4696.2011.

[4] Ting-Yu Chen. The inclusion-based TOPSIS method with interval-valued intuitionistic fuzzy sets for multiple criteria group decision making. Applied Soft Computing. 26 (5), pp. 57-73,2015.

[5] senija Mandic, Boris Delibasic, Snezana Knezevic, Sladjana Benkovic. Analysis of the financial parameters of Serbian banks through the application of the fuzzy AHP and TOPSIS methods. Economic Modelling. 43 (4), pp. 30-37,2014.

[6] Zheng-Xin Wang, Yan-Yu Wang. Evaluation of the provincial competitiveness of the Chinese high-tech industry using an improved TOPSIS method. Expert Systems with Applications., 41 (14), pp. 2824-2831,2014.

[7] Amelia Bilbao-Terol, Mar Arenas-Parra, Verónica Cañal-Fernández, José Antomil-Ibias. Using TOPSIS for assessing the sustainability of government bond funds. Omega. 49, pp. 1-17, 2014.

[8] Mohit Tyagi, Pradeep Kumar, Dinesh Kumar. A Hybrid Approach using AHP-TOPSIS for Analyzing e-SCM Performance. Procedia Engineering. 97, pp. 2195-2203, 2014. 